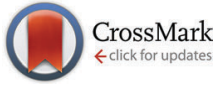

Cite this: New J. Chem., 2016, 40, 1039

Received (in Montpellier, France) 9th October 2015 .

Accepted 12th January 2016

DOI: $10.1039 / c 5 n j 02775 f$

www.rsc.org/njc

\section{In vitro cell cytotoxicity profile and morphological response to polyoxometalate-stabilised gold nanoparticles $\dagger$}

\author{
Isabel Maicas Gabas, $\ddagger^{a}$ Grazyna Stepien, $\ddagger^{a}$ María Moros, ${ }^{* c}$ Scott G. Mitchell*b and \\ Jesús M. de la Fuente ${ }^{b}$
}

\begin{abstract}
The size and redox properties of molecular polyoxometalates (POMs) make them extremely relevant for bioapplications: from disrupting tumour growth and enzyme inhibition, to DNA-intercalating agents and antimicrobial applications. Their unique ability to reversibly dominate and receive electrons, coupled with their high anionic charge, also makes them suitable for the preparation of zero-valent state metal nanoparticles (NPs) from molecular precursors. Polyoxometalate-stabilised nanoparticles (NPs@POM) are therefore an ideal delivery vehicle for bioactive POMs. Here we show how POM-stabilised gold NPs (AuNPs(aPOM) are massively internalised into Vero (kidney epithelial) and B16 (skin melanoma) cell lines with variable cytotoxic effects. Cell viability assays and quantification of cytoplasmic membrane composition revealed that the Vero cell line was unaltered by the internalisation of these hybrid particles; while their internalisation in B16 tumour cells produced mild cytotoxic effects and an antiproliferative cell cycle arrest in the G0/G1 and G2/M phases. The observed perturbation of the tumour cell line combined with the high degree of internalisation means that these (or similar) NPs@POM could serve as candidates for a range of bioapplications in diagnostics or therapy.
\end{abstract}

\section{Introduction}

The size-dependent physicochemical properties of colloidal nanomaterials can be tuned to achieve enhanced or specific magnetic, optical and electronic properties when compared to their constituent parts. ${ }^{1}$ The combination of their nanometre size and their unique physiochemical features enable nanomaterials to operate at the biomolecular level, lending them to a wide variety of applications for biomedical and biotechnological applications such as photothermal therapy, ${ }^{2}$ optoacoustic imaging ${ }^{3}$ as well as colorimetric and thermal biosensors. ${ }^{4}$ The properties of gold and magnetic nanoparticles (NPs) lend themselves particularly well to applications relating to diagnosis, drug delivery, imaging, treatment and theranostics. ${ }^{5}$ The combination of nanoparticle size, shape and surface chemistry exerts significant influence on their

\footnotetext{
${ }^{a}$ Instituto de Nanociencia de Aragón (INA), Universidad de Zaragoza, Spain

${ }^{b}$ Instituto de Ciencia de Materiales de Aragón-CSIC/Universidad de Zaragoza, Spain.E-mail: scott@unizar.es

${ }^{c}$ Istituto di Scienze Applicate e Sistemi Intelligenti-CNR, Pozzuoli, Naples, Italy. E-mail:m.moros@isasi.cnr.it

$\dagger$ Electronic supplementary information (ESI) available: MTT control cell viability assays for the molecular Kabanos POM in the Vero and B16 cell lines as well as point-and-shoot EDX, DLS and $\zeta$-potential measurements of the AuNPs@POM. See DOI: $10.1039 / \mathrm{c} 5 \mathrm{nj} 02775 \mathrm{f}$

\# These authors contributed equally to this publication.
}

desired function. ${ }^{6}$ The overwhelming diversity of NP size and shape is determined by a combination of thermodynamic (i.e. temperature, reduction potential) and kinetic factors (i.e. reactant concentration, diffusion, solubility concentration rate) during synthesis, ${ }^{7}$ while the type of capping/stabilising agent can be modified either during or post-synthesis of the particles. ${ }^{8}$ Stabilising agents act to prevent NPs from agglomerating and most commonly are small organic molecules or polymeric materials.

Polyoxometalates (herein POMs) are oligomeric aggregates of metal cations (usually the $\mathrm{d}^{0}$ species $\mathrm{V}(\mathrm{v}), \mathrm{Nb}(\mathrm{v}), \mathrm{Ta}(\mathrm{v}), \mathrm{Mo}(\mathrm{vI})$, and $\mathrm{W}(\mathrm{vI})$ ) bridged by oxide anions that form by self-assembly processes. ${ }^{9}$ Due to their unique ability to reversibly accept and release electrons without change in their structural conformation, ${ }^{10}$ POMs are model electron-transfer catalysts and can act as reducing agents for preparation of a wide variety of metallic NPs such as Pt, $\mathrm{Pd}, \mathrm{Ru}, \mathrm{Au}$ and $\mathrm{Ag} .{ }^{11}$ Importantly, the high negative charge of POMs also makes them ideal electrostatic stabilising agents to the forming NPs. ${ }^{12}$ Although POMs are traditionally employed in catalysis, ${ }^{13}$ they have also been shown to be extremely efficient inorganic antiviral, antitumoural and antimicrobial agents. ${ }^{14}$ Hill and co-workers, who have contributed a great deal to POM antiviral research, reviewed the use of POMs in medicine almost 20 years ago. ${ }^{15}$ A decade ago Yamase reviewed the most recent advances in antimicrobial and antitumoural applications of POMs. ${ }^{14}$ Although several stimulating and insightful reports have been 
published recently, the use of POMs in medicine has largely fallen by the wayside. One reason for this may be because, at least in practical terms, if POMs are to be used as novel drugs, drug-delivery agents, sensors, antimicrobial agents and so forth, an understanding of the cellular behaviour and location of POMs (or POM conjugates) is critical, and unfortunately these remain poorly studied and little understood. It is generally acknowledged that non-covalent binding influenced by the size, shape, and charge density of POMs is the key to their biological activity, yet very little is known about the reactivity of POMs towards biological molecules. For example, although the cellular cytotoxicity and internalisation of POM-based nanomaterials has been profiled ${ }^{16}$ a recent review has discussed how extracellular target proteins as well as proteins integrated into the cell membrane with binding sites accessible from the extracellular space are the most likely sites of interaction with POMs and are the most likely factors affecting their pharmacological activity. ${ }^{17}$ Recent work on POMs as artificial proteases ${ }^{18}$ and non-enzymatic peptidases ${ }^{19}$ is contributing substantially to this area.

Yet for POMs to be used more abundantly in diagnostics or therapy they clearly benefit from being supported in order to increase dispersion of the 'active' POM. Furthermore, site-specific delivery could also be addressed, for example by using POM-coated magnetic NPs, or NPs covered with peptide-conjugated POMs. NPs undoubtedly provide useful and convenient supports for POMs with respect to bioapplications and gold nanoparticles (AuNPs) ${ }^{20}$ offer a convenient starting point for in vitro studies on NP@POM hybrid materials for several reasons. POM-stabilised AuNPs (AuNPs@POM) are now well-known and their nanometre size (typically 10-50 nm), optical properties and high electron density means that their cellular uptake and intracellular location can be studied using dark field and electron microscopies.

We have recently reported a combined theoretical/experimental approach to the synthesis of pseudo-spherical AuNPs@POMs where AuNPs of diameter ca. $29 \mathrm{~nm}$ were synthesised and stabilised with the Kabanos-type POM $\left[\mathrm{Na}\left\{\left(\mathrm{Mo}_{2}^{\mathrm{V}} \mathrm{O}_{4}\right)_{3}\left(\mu_{2}-\mathrm{O}\right)_{3^{-}}\right.\right.$ $\left.\left.\left(\mu_{2}-\mathrm{SO}_{3}\right)_{3}\left(\mu_{6}-\mathrm{SO}_{3}\right)\right\}_{2}\right]^{15-21}$ We wanted to investigate the behaviour of these same all-inorganic AuNPs@POM in vitro. By doing so we aimed to study their cell-internalisation capacity and investigate whether their internalisation triggered any cytotoxic effects. Herein we report in vitro studies on AuNPs@POM detailing their cellular uptake and cytotoxicity at different levels in Vero (kidney epithelial) and B16 (mouse melanoma) cell lines.

\section{Results and discussion}

Synthesis of polyoxometalate-stabilised gold nanoparticles (AuNPs@POM)

Both the Kabanos-type $\mathrm{POM}^{22}\left[\mathrm{Na}\left\{\left(\mathrm{Mo}_{2}^{\mathrm{V}} \mathrm{O}_{4}\right)_{3}\left(\mu_{2}-\mathrm{O}\right)_{3}\left(\mu_{2}-\mathrm{SO}_{3}\right)_{3}\right.\right.$ $\left.\left.\left(\mu_{6}-\mathrm{SO}_{3}\right)\right\}_{2}\right]^{15-}$ and the AuNPs@POM ${ }^{21}$ were synthesised according to reported experimental procedures. The non-classical Kabanos POM was chosen for this work because it contains two layers of hexanuclear polyoxomolybdenum(v) sulfite anions with all Mo atoms in a one-electron reduced oxidation state, $\mathrm{Mo}(\mathrm{v})$, meaning that it has 'in-built' reduction capabilities, i.e. no need for electro- or

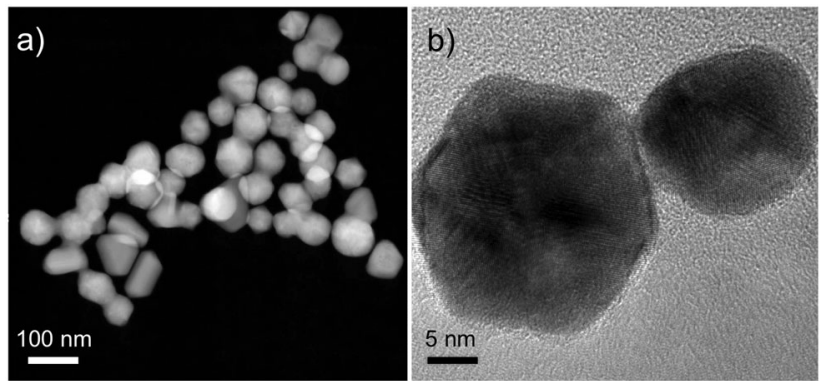

Fig. 1 (a) HAADF-STEM and (b) HR-TEM images of AuNPs@POM.

photo-reduction of the POM prior to their use in the synthesis of AuNPs. ${ }^{23}$ Briefly, AuNPs@POM were formed by adding $50 \mathrm{mg}$ $(0.019 \mathrm{mmol})$ of $\left[\mathrm{Na}\left\{\left(\mathrm{Mo}_{2}^{\mathrm{V}} \mathrm{O}_{4}\right)_{3}\left(\mu_{2}-\mathrm{O}\right)_{3}\left(\mu_{2}-\mathrm{SO}_{3}\right)_{3}\left(\mu_{6}-\mathrm{SO}_{3}\right)\right\}_{2}\right]^{15-}$ single crystals to $100 \mathrm{~mL} 0.667 \mathrm{mM} \mathrm{HAuCl}_{4}(\mathrm{aq})$ at $\mathrm{pH} 5$ under magnetic stirring. The pale yellow colour of the $\mathrm{Au}^{\mathrm{III}}$ chloroauric acid solution quickly turned transparent upon addition of the POM, turning dark red after several minutes. After $30 \mathrm{~min}$, UV-vis spectroscopy analysis of the colloidal material showed one dominant localised surface plasmon resonance (LSPR) band at $535 \mathrm{~nm}$ corresponding to polyhedral gold nanoparticles. The colloidal material was washed with Milli-Q water to remove unwanted by-products (including a minor amount of triangular gold nanoprisms) and reagents via multiple centrifugation/resuspension steps. Transmission Electron Microscopy (TEM) characterisation of the AuNPs@POM was used to obtain additional information on the size and shape of the nanoparticles which possessed a mean diameter of $29 \mathrm{~nm}$. FTIR, XPS and EDX analysis of dried AuNPs and ICP analysis of a digested sample comprehensively confirm the presence of an oxomolybdate species stabilising the surface of the AuNPs (Fig. 1). $\S^{21}$

\section{Suitability of AuNPs@POM for cell studies}

In the first instance, before any cell studies were performed the sterilisation of these particular hybrid NPs had to be evaluated, along with their potential to aggregate and precipitate in cell culture media. Monodisperse AuNPs@POM were sterilised by passing them through a $0.2 \mu \mathrm{m}$ PVDF membrane filter, because other sterilisation techniques can severely affect the integrity of the physicochemical properties of AuNPs. ${ }^{24}$

Once the AuNPs@POM had been successfully filtered and showed no signs of aggregation, they were incubated in DMEM (Dulbecco's Modified Eagle Medium) containing 10\% of inactivated foetal bovine serum (FBS) for $24 \mathrm{~h}$ at $37{ }^{\circ} \mathrm{C}$. Unspecific adsorption of proteins from the culture media onto the surface of the NPs (protein corona) can lead to the NP aggregation. This aggregation can influence the interaction of the NPs with the cells, since cellular uptake depends heavily on both their size and morphology. ${ }^{25}$

The absence of any signs of aggregation by optical microscopy e.g. $\mathrm{Au}^{0}$ deposits on the bottom of well-plates, cloudy precipitate in the cell medium, meant that the cell studies could proceed as planned. Prior to assessing the in vitro toxicity profile of the NPs, we aimed to expose the precise location of the AuNPs@POM

$\S$ Please refer to ref. 21 for full experimental and characterisation details for the AuNPs@POM. 
accumulated within cells, so their cell-internalisation was assessed using Transmission Electron Microscopy (TEM).

\section{Morphological analysis of cells using transmission electron microscopy}

The precise location of nanoparticles within the cells was obtained using resin-bound cells that were cut with a microtome into ultra-thin slices and stained for electron microscopy investigations. The representative B16 cell sample was incubated with $0.1 \mathrm{mg} \mathrm{mL}^{-1}$ AuNPs@POM for $24 \mathrm{~h}$ prior being fixed with glutaraldehyde, post-fixed with osmium tetroxide and embedded in Durcupan resin. Semi-thin $1.5 \mu \mathrm{m}$ sections were cut several times until ultra-thin sections of $<0.08 \mu \mathrm{m}$ were obtained. Samples were stained lightly with toluidine blue for TEM imaging. A reference B16 cell sample was left untreated as a control.

TEM analysis of the treated cells shows that no significant morphological differences were observed after treatment when compared with the control cells, specifically, no autophagic features, e.g. vesicles were observed. Importantly, for the B16 cells treated with AuNPs@POM several high contrast regions corresponding to considerable amounts of NPs were observed (Fig. 2). Selected areas were investigated at higher magnifications as shown in Fig. 2e and $\mathrm{f}$. The dark contrast is due to the high electron density of the AuNPs and it is clear that the majority of these particles are located in the cytoplasm, contained entirely within the endosomes. While each endosome was filled with several hundred AuNPs@POM, none were observed close to (or associated with) the cell membrane.

The electron microscopy studies of the resin-bound B16 cells pinpointed the precise location of the AuNPs@POM within the cells and showed an apparent absence of morphological changes, commensurate with a relative lack of cytotoxicity.

\section{In vitro cell toxicity assays}

To date, there are no standardised protocols for assessing the toxicity of the NPs. It has been widely reported that the cytotoxicity depends on many factors, such as the size, shape, composition of the NP, cellular line, incubation time or even the selected assay. ${ }^{26}$ It is therefore clear that to test the cytotoxicity different cell lines must be used due to possible differences in their origin and proliferative capacity. ${ }^{24}$ Furthermore, the use of different cell viability assays will led to a deeper understanding of any observed cytotoxic effects.

Cell viability assays. In the first instance, the viability of cells treated with AuNPs@POM was investigated using MTT assays, a colorimetric assay for assessing cell viability. MTT [3-(4,5dimethylthiazol-2-yl)-2,5-diphenyltetrazolium bromide] is a yellow tetrazole dye that is reduced to its insoluble form, purple formazan crystals, by the NAD(P)H-dependent succinate dehydrogenase, a mitochondrial enzyme in living cells. Thus reflecting, under defined conditions, the number of viable living cells present in the sample. For that purpose B16 and Vero cells were incubated with various concentrations of AuNPs@POM for $24 \mathrm{~h}$. Afterwards the cells were thoroughly washed with PBS and incubated with MTT as described in experimental section. Results for different concentrations are shown in Chart 1 . Sextets were performed (twice)
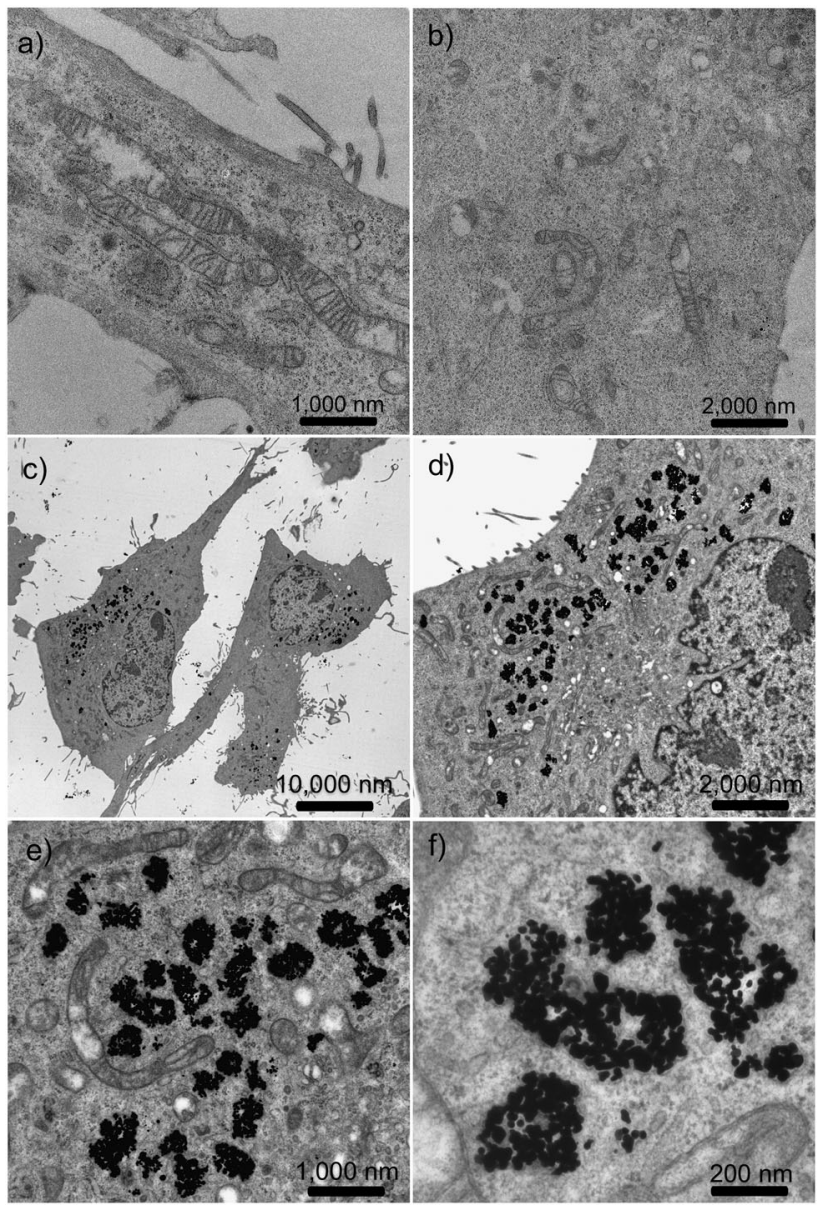

Fig. 2 (a and b) Representative survey image of untreated B16 cells (control: no AuNPs(aPOM); (c-f) B16 cells treated with $0.1 \mathrm{mg} \mathrm{mL} \mathrm{mL}^{-1}$ AuNPs@POM clearly exhibiting the internalisation of the hybrid particles. Higher magnifications ( $\mathrm{e}$ and $\mathrm{f}$ ) pinpoint their location within endosomes. AuNPs@POM were not found associated to the cell membrane, nor were they observed within the nucleus.

for the control experiments and for each concentration of AuNPs@ POM to determine the standard deviation and reproducibility of the results.

The MTT analysis revealed that the AuNPs@POM do not cause excessive cell death after $24 \mathrm{~h}$ incubation at the tested concentrations, especially in the case of Vero cells (Chart 1). In Vero cells (Chart 1a), the percentage of living cells was ca. 90-93\% in all tested concentrations. However, in B16 cells (Chart 1b), the effect was more pronounced, and cell viability was already impaired at the lowest tested concentration in comparison with the control sample. At higher AuNPs@POM concentrations, a more significant decrease of the B16 viability was observed and at $0.1 \mathrm{mg} \mathrm{mL}$ viability was 72\%. These findings demonstrate that AuNPs@POM do exert cytotoxic action and affect the normal proliferation in B16 cells, contributing to their deleterious effect on this particular tumour cell line. It is noteworthy that control MTT cell viability assays of the molecular POM at the same concentrations found on the AuNP surface, show that the POM alone has less cytotoxic effect and only exerts minor antiproliferative action in B16 cells at significantly elevated concentrations (Graph S1, ESI $\dagger$ ). As a result 
a)

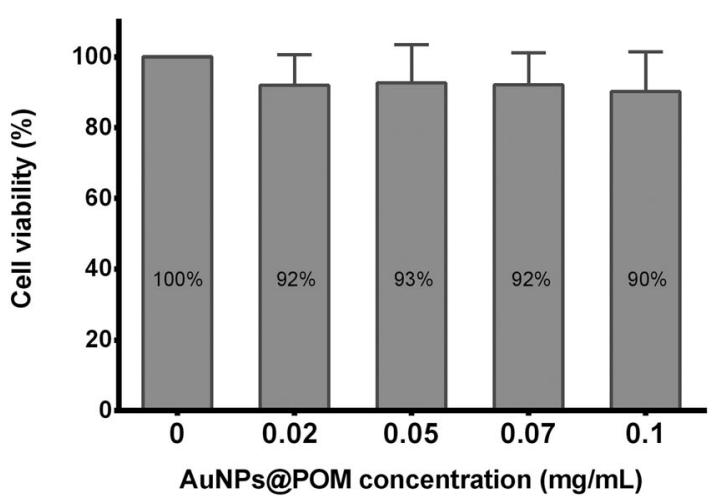

b)

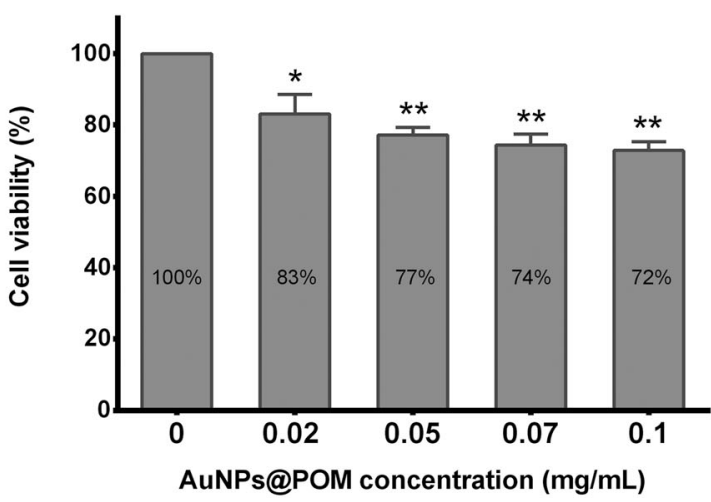

Chart 1 ( $a$ and $b$ ) Concentration-dependent MTT assay cell viability results of AuNPs@POM incubated for $24 \mathrm{~h}$ at $37{ }^{\circ} \mathrm{C}$ with Vero and B16 cells, respectively. The measured absorbance from control (blank cells without AuNPs(POM) was treated as $100 \%$ of viable cells. Black asterisks show AuNPs@POM concentrations at which the viability was found to be statistically significant in comparison with control cells $\left({ }^{\star} p<0.05,{ }^{* *} p<0.01\right)$.

we postulate that it is the synergic combination of POM with AuNP in the AuNPs@POM hybrids that induces observed cellular toxicity in B16 cells, possibly affecting the transmembrane receptor(s) (Chart 1b).

Although MTT assays have routinely been performed on molecular $\mathrm{POMs}^{27}$ currently there are very little available data concerning MTT assays on POM-stabilised NPs. However, a recent report discussing tyrosine-reduced AgNPs with phosphotungstic acid or phosphomolybdic acid surface coronas as antimicrobial agents also detailed concentration dependent MTT assays against human PC3 epithelial cells. ${ }^{28}$ Although these particular AgNPs demonstrated significant antibacterial activity against Escherichia coli and Staphylococcus albus, none of the particles showed any significant toxicity, morphology or cell density changes to the PC3 cells up to the highest concentrations. In 2011, Patzke and co-workers reported MTT assays for supramolecular $\left\{\mathrm{EuSiW}_{11} \mathrm{O}_{19}\right\}$ carboxymethyl chitosan nanocomposites. ${ }^{16}$ They reported that the viability of HeLa cells decreased to $80 \%$ upon extended incubation times ( 24 and $48 \mathrm{~h}$ ) at the maximum tested POM concentration $\left(2 \mathrm{mg} \mathrm{mL}{ }^{-1}\right.$ ), whereas POMs encapsulated in the chitosan nanocomposite produced no cytotoxic effects at the same concentrations. Another recent study used MTT to evaluate the use of 'Mo POM NPs' to inhibit tumour growth and vascular endothelial growth factor induced angiogenesis; however, the tested compounds were not colloidal nanocrystals coated with POMs, but rather archetypal nanoscale POM clusters. ${ }^{29}$ Nevertheless, it is worth mentioning that the authors reported MTT assays on Human Umbilical Vein Endothelial Cells (HUVECs), human hepatocellular liver carcinoma cells (HepG2), human melanoma cells (A375), breast cancer cells (MCF-7), and human low differentiation nasopharyngeal carcinoma cells (CNE-2). High cytotoxic effects of 'Mo POM NPs' against HepG2 tumoural cells and HUVEC cells indicated that these 'Mo POM NPs' showed higher preference in the HUVEC and HepG2 cells on cell proliferation.

Consequently, in order to more precisely quantify the cytotoxicity profile of the AuNPs@POM in Vero and B16 cells and to investigate the apparent difference in response to internalised particles, flow cytometry analysis was performed to quantify the apoptosis/necrosis in each cell line.

Quantification of apoptosis/necrosis. Cell analysis by flow cytometry allows a more accurate quantification of cell viability by obtaining representative populations of viable (living), apoptotic (dying) and necrotic (dead) cells following incubation with various concentrations of AuNPs@POM. Apoptosis is a form of genetically encoded (programmed) cell death - a capability possessed by all cells. Apoptotic cells are inactivated, disassembled and prepared to degrade their own structure and components in a characteristic and coordinated way. One of the early events in apoptosis is the expression of cell surface markers. During apoptotic cell death, phosphatidylserine translocates from the internal to the external face of the plasma membrane, exposing it to the extracellular side. Annexin V (AnnV) has a specific affinity for the phosphatidylserine, therefore attached to a fluorochrome such as FITC, is widely used to detect cells undergoing apoptosis. On the other hand, propidium iodide (PI) is a DNA-intercalating agent that commonly used to evaluate membrane integrity due to the fact that this molecule is only able penetrate the plasma membrane of a cell when the membrane is disrupted. A disrupted plasma membrane is typical of necrosis and late apoptosis. Flow cytometry can thus easily distinguish between living (AnnV- PI-), apoptotic (AnnV+ PI-), necrotic $(\mathrm{AnnV}-\mathrm{PI}+)$ and late apoptotic/secondary necrotic $(\mathrm{AnnV}+\mathrm{PI}+)$ cells.

For Vero cells incubated with AuNPs@POM at all of the aforementioned concentrations (from $0.02-0.1 \mathrm{mg} \mathrm{mL}^{-1}$ ) for $24 \mathrm{~h}$, approximately $93-95 \%$ were shown to be alive, $5-6 \%$ necrotic and $0.1-0.3 \%$ apoptotic, with very little variation amongst each of the tested concentrations (Fig. 3a). This data is commensurate with little or no toxicity when compared to the control sample. The same experiments in the B16 cell line showed little variation on this theme until the highest tested concentration (Fig. 3b). Upon incubation with $0.1 \mathrm{mg} \mathrm{mL}^{-1}$ particles where the number of living cells dropped to $90 \%$ and necrotic cells increased to almost $10 \%$, illustrating a general cytotoxicity trend.

From this analysis of cytoplasmic membrane integrity it is evident that, compared to control experiments, there is no significant cytotoxicity to the Vero cell population at the tested concentrations of AuNPs@POM; while a cytotoxicity trend is 

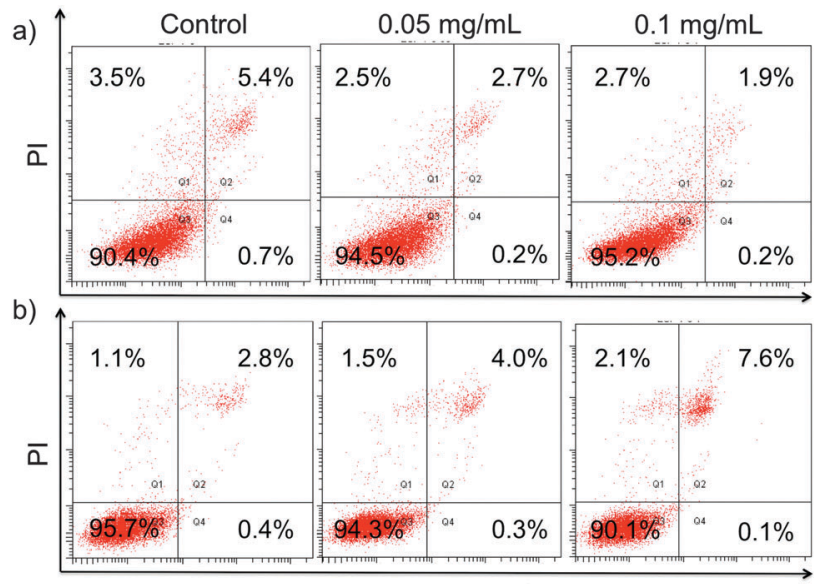

AnnexinV-FITC

Fig. 3 Concentration-dependent cell apoptosis/necrosis effects induced in (a) Vero and (b) B16 cells following incubation with AuNPs@POM at $37^{\circ} \mathrm{C}$ for $24 \mathrm{~h}$. Cells were double-stained with annexin V/propidium iodide (PI) and analysed by flow cytometry.

evident in the B16 tumour cell line (Fig. 3). The general trend is that the particles are non-toxic at lower concentrations, but that the B16 cell line is more susceptible to the internalisation of the particles. It is also important to note that the differences between the MTT assays and flow cytometry data are much more pronounced in B16 than for Vero cells. It must be pointed out that MTT assays are suitable for the determination of viable cells, but cannot distinguish between quiescent or actively dividing cells. Therefore to gain more insight into the possible toxicity at the cellular level, we studied cell cycle analysis to determine the influence of the AuNPs@POM on cell division and proliferation.

Cell cycle analysis. The cell cycle is the process by which eukaryotic cells duplicate and divide. The cell cycle consists of different phases, tightly regulated: interphase where a cell grows, replicates DNA and prepares to divide, and a mitotic phase (M), were the cell divides into two daughter cells. Interphase consist in different steps: G1 (grow), S (synthesis), and G2 (prepare to divide). To detect potential DNA damage checkpoints exist, and each of the phases of the cell cycle are strictly regulated. Apoptotic cells can be identified in subG1 phase. To assess the cell cycle by DNA content, cells were stained with propidium iodide (PI) and analysed using flow cytometry. The stoichiometric binding of PI to DNA means that the amount of cellular DNA can be quantified via the amount of fluorescent signal recorded.

The presence of the AuNPs@POM in treated cells in each phase of the cell cycle was compared to the control cells (no particles). In Vero cells, none of the tested concentrations evoked significant changes in the cell cycle phases (Fig. 4a). However, the AuNPs@POM led to a significant perturbation in the B16 cell cycle (Fig. 4b). Indeed, for the B16 cell line an accumulation of cells (cell cycle arrest) in G0/G1 and G2/M phases occurred, with a concurrent reduction of the cell population in $\mathrm{S}$ phase. As expected, and in line with the previous apoptosis/ necrosis studies (Fig. 3b), no increment in the apoptotic fraction was found (Sub G1). These results suggest that the AuNPs@POM promote DNA damage in B16 cells, given that this effect is generally accompanied by cell cycle arrest, although further experiments should be conducted to prove this. Importantly, arrest in G0/G1 or G2/M phases have been extensively described with antitumoural drugs, ${ }^{30}$ different types of $\mathrm{NPs}^{31}$ and even polyoxometalates. ${ }^{32}$

\section{Quantification of the cell internalisation of AuNPs@POM}

Accordingly we wanted to better understand the susceptibility of the B16 cell line to AuNPs@POM and, based on the significant internalisation observed from TEM images, postulated that it was due to a higher internalisation of the particles when compared with the Vero line. To quantify the internalised particles within both Vero and B16 cells comprehensive ICP analyses were performed. In order to do this only the highest concentration of $0.1 \mathrm{mg} \mathrm{mL}{ }^{-1}$ was selected for incubation with Vero and B16 and each analysis was performed in duplicate to verify reproducibility. Therefore, after $24 \mathrm{~h}$ of incubation with $0.1 \mathrm{mg} \mathrm{mL}^{-1}$ AuNPs@POM, cells were washed thrice with PBS a)

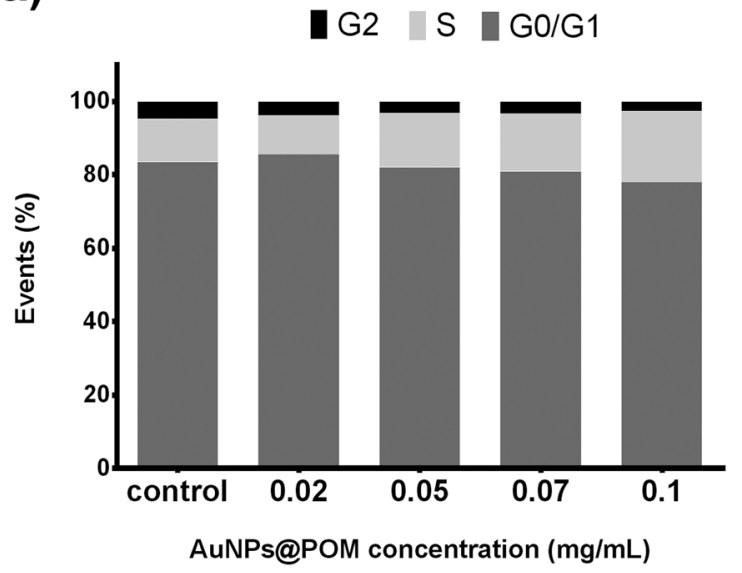

b)

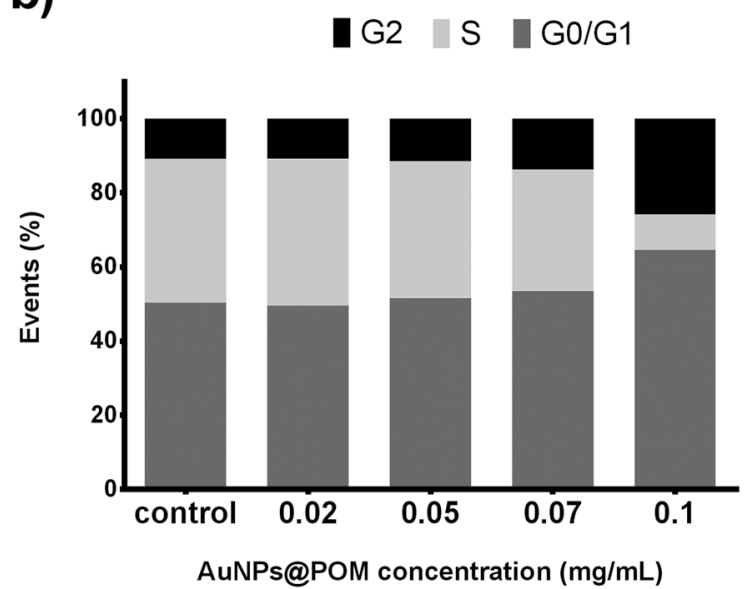

Fig. 4 Concentration-dependent effect of AuNPs@POM on cell cycle arrest and DNA fragmentation in: (a) Vero and (b) B16 cells. Cells were incubated with different concentrations of AuNPs@POM for $24 \mathrm{~h}$ at $37^{\circ} \mathrm{C}$ and cell cycle analysis was assessed using a PI stain and flow cytometry. 
and digested first with piranha solution and then with aqua regia for 1 and $3 \mathrm{~h}$, respectively. Finally, all samples were incubated at $60{ }^{\circ} \mathrm{C}$ for $15 \mathrm{~min}$ and diluted with Milli-Q water. To calculate the $\mathrm{Au}$ content per cell, the same number of B16 and Vero cells were seeded but were left blank (no NPs were added) for the same period of time as samples treated with AuNPs@POM. This enabled us to count the number of cells using Trypan blue.

ICP analysis revealed that B16 cells incorporated $42 \%$ of all administrated AuNPs@POM, where each individual cell assimilated $21 \mathrm{pg}$ of Au. Surprisingly, Vero cells internalised 58\% of the administered AuNPs@POM, giving a total of 34 pg of Au per cell. The higher amount of AuNPs@POM internalised by the Vero cells was not in agreement with our original hypothesis, where we expected higher internalisation by the B16 tumoural cells. But despite the massive internalisation of AuNPs, the Vero cells remain largely unaffected by the administered dose. Importantly, these differences in cellular uptake of the AuNPs@POM from one cell type to another can be ascribed to the diverse uptake efficiency of the two investigated lines (each cell line displays different kinetics, endocytosis mechanisms, cellular metabolism, and so forth). ${ }^{33}$ On the other hand, MTT assays, apoptosis/necrosis and cell cycle data have shown that the AuNPs@POM are more toxic to the B16 cells despite the lower internalisation when compared to the Vero cells. Remarkably, analysis of the Mo content shows that B16 and Vero cells internalised $91 \mathrm{fg}$ and $21 \mathrm{fg}$ per cell, respectively. Therefore one hypothesis is that the observed toxicity to the B16 tumoural cell line is associated with the AuNP mediated delivery of high concentrations of Mo into the cells. It is important to note, however, that the accumulation of NPs in both cell types is exceptionally large and it is remarkable that the Vero cell line remains largely unaffected by the presence of such large quantities of internalised NPs, while the same particles exert a pronounced antiproliferative action on the B16 tumoural cell line.

\section{Conclusions}

In summary, we report how polyoxometalate-stabilised gold nanoparticles (AuNPs@POM) internalise readily and in vast quantities into Vero (kidney epithelial) and B16 (skin melanoma cells) cell lines. All together, our results indicate that AuNPs@POM caused greater antiproliferative action on B16 tumour cells than on Vero cells.

TEM imaging shows that the AuNPs@POM are located in the endosomes, far from the nucleus of the cells and that none are associated to the cytoplasmic membrane. The results of MTT cell viability assays coupled with apoptosis/necrosis studies by flow cytometry reveal that Vero cells remain largely unaltered by the internalisation of these hybrid particles, while the viability of the B16 cell line was affected at the highest tested concentrations. The deleterious effects in B16 cells was verified by analysing the cellular cycle. Control cell viability assays (ESI $\dagger$ ) showed that the molecular POM species at the same concentrations found on the AuNPs@POM were ineffective against either cell line, thus illustrating some sort of synergistic antiproliferative effect of the AuNPs@POM on B16 tumoural cells.
The cytotoxicity profile of these hybrid POM-stabilised NPs in normal $v s$. tumoural cell lines coupled with the high degree of internalisation (determined from ICP analysis) means that these (or similar) hybrid particles could serve as candidates for a range of applications in diagnostics or therapy, for example as potential antitumour therapies. These results provide new insights into POM chemistry and nanoparticle science and the antiproliferative action of the particles in B16 cells poses motivating questions to stimulate new avenues of research.

There are various potential mechanisms through which these hybrid particles may exert their cytotoxic effect on B16 cells, and more extensive investigations will be needed to elucidate the exact cellular-internalisation pathway(s) and inhibitory mechanism(s) through which these particles operate. In this respect, the use of fluorescently labelled POMs would greatly facilitate this endeavour, where additional in vitro information could be gained using dark field microscopy to pinpoint the AuNPs, coupled with confocal and/or optical microscopy to locate the labelled POM. Concerning any potential medical applications of these hybrid materials, the selection of POMs that will exert a desired (antimicrobial, antitumoural or antiviral) response that are loaded onto nanoparticle supports for efficient delivery to cells will be critical. For increased specificity, click chemistry could be used ${ }^{34}$ to conjugate cell-penetrating peptides to the POM to direct the payload to its desired location, further increasing the efficacy of the bioactive POM. $^{35}$

\section{Experimental}

\section{Materials and methods}

All chemicals and solvents were of analytical grade purchased from Sigma Aldrich and used as supplied, without further purification. Pure water was used throughout by passing water through a Millipore-Q Academic purification set. UV-vis Spectroscopy: all samples were measured in aqueous suspension at room temperature using a Varian Cary $50 \mathrm{UV}$-visible spectrometer over the range of 200-1100 $\mathrm{nm}$ in $1 \mathrm{~cm}$ quartz cuvettes. High-Resolution Transmission Electron Microscopy (HR-TEM): all samples were deposited on carbon-covered $\mathrm{Cu} 200$ mesh grids and data were collected on a FEI Tecnai TF20 $200 \mathrm{kV}$ FEG high resolution TEM. Inductively coupled plasma atomic emission spectroscopy (ICP-AES): data were collected under Argon gas using an IRIS Intrepid Radial Thermoelemental equipped with an Echelle optical system (381 $\mathrm{mm}$ ) and a solid state Charge Injection Device (CID) $(28 \mu \mathrm{m} \times 28 \mu \mathrm{m})$. Flow Cytometry: cell membrane integrity was measured on a $\mathrm{BD}$ Biosciences FACSAria $^{\mathrm{TM}}$ (Becton Dickinson Company) cell sorter using a commercial staining kit from IMMUNOSTEP (ref: ANXVFK-100T); the cell cycle analysis was analysed using a FACSArray $^{\mathrm{TM}}$ (Becton Dickinson Company) cell sorter using propidium iodide (PI) stain.

\section{Preparation of AuNPs@POM}

The AuNPs@POM were prepared and characterised according to a reported experimental procedure. ${ }^{21}$ 


\section{Cell lines}

Vero are kidney epithelial cells from African green monkey (Cercopithecus aethiops). B16 are skin melanoma cells lines isolated from mouse (Mus musculus). Both cells lines were acquired from the American Type Culture Collection (ATCC): Vero (CCL-81) and B16 (CRL-6475).

Cells were cultured at $37{ }^{\circ} \mathrm{C}$ in a $5 \% \mathrm{CO}_{2}$ atmosphere in Dulbecco's modified Eagle's medium (DMEM) (Lonza) supplemented with $10 \%$ foetal bovine serum (FBS), $5 \%$ glutamine and $5 \%$ penicillin/streptomycin.

\section{Transmission electron microscopy analysis of fixed cells}

$2 \times 10^{4}$ of B16 cells were seeded in an 8-well chamberslide (permanox, Nunc) and allowed to replicate overnight at $37{ }^{\circ} \mathrm{C}$ ( $5 \%$ of $\mathrm{CO}_{2}$ and humidified atmosphere). Thereafter, cells were incubated with $0.1 \mathrm{mg} \mathrm{mL}^{-1}$ of AuNPs@POM for $24 \mathrm{~h}$ then washed with PBS to remove free particles before being fixed with $2.5 \%$ glutaraldehyde in $0.1 \mathrm{M}$ phosphate buffered saline (PBS) for 1 hour at $4{ }^{\circ} \mathrm{C}$. The cells were then washed four times with $0.1 \mathrm{M}$ PBS. Sections were post-fixed with $2 \%$ osmium tetroxide, rinsed, dehydrated and embedded in Durcupan resin (Fluka, Sigma-Aldrich, St. Louis, USA). Semi-thin sections $(1.5 \mu \mathrm{m})$ were cut with an Ultracut UC-6 (Leica, Heidelberg, Germany) and stained lightly with $1 \%$ toluidine blue. Finally, ultra-thin sections $(0.08 \mu \mathrm{m})$ were cut with the microtome, stained with lead citrate (Reynolds solution) and examined under a $200 \mathrm{keV}$ FEI Tecnai T20 (FEI Europe, Eindhoven, Netherlands) operating at $80 \mathrm{keV}$.

\section{MTT cell viability assays}

Vero or B16 cells were seeded in 96-multiwell plate at a density of $1 \times 10^{4}$ cells per well and incubated overnight at $37{ }^{\circ} \mathrm{C}(5 \%$ $\mathrm{CO}_{2}$ and humidified atmosphere). After 24 hours the medium was replaced with a fresh DMEM for the positive controls (100\% cell viability) and with DMEM with the AuNPs@POM adjusted to the desired concentrations $(0.1,0.07,0.05$ and $0.02 \mathrm{mg} \mathrm{mL} \mathrm{m}^{-1}$ ). It is important to note that the water content of the nanoparticle suspensions was always less than $10 \%$, i.e. to obtain the final concentration of AuNPs@POM the original suspensions were centrifuged to remove water and diluted to the desired volume with DMEM so that the final volume contained no more than $10 \%$ water. All cells were incubated for 24 hours prior to performing the MTT assay. Excess medium was removed and the cells were washed trice with PBS (to remove any excess non-internalized particles and dead cells) and then $200 \mu \mathrm{L}$ of DMEM containing $20 \mu \mathrm{L}$ of MTT (3-(4,5-dimethylthiazol-2-yl)-2,5diphenyltetrazolium bromide) $5 \mathrm{mg} \mathrm{mL}{ }^{-1}$ was added to the cells. The 96-multiwell plate was incubated in the dark for three hours and centrifuged (one hour, $1260 \mathrm{rpm}$ ). MTT is converted by living cells into violet formazan crystals and this metabolic product was solubilised by replacement of the MTT-containing medium with $200 \mu \mathrm{L}$ of dimethyl sulfoxide (DMSO). After mixing, the optical density at $570 \mathrm{~nm}$ was recorded using a plate reader (ELx800TM, Biotek (Thermo Scientific Multiskan GO UV/Vis microplate spectrophotometer)). Sextets were performed (twice) for the control experiments and for each concentration of AuNPs@POM to determine the standard deviation and reproducibility of the results. Statistical analysis: one-way Anova for B16 and for Vero (separately) and Tukey's multiple comparison test were performed using the GraphPadPrism software.

\section{Quantification of apoptosis/necrosis by flow cytometry}

Cells were seeded in 12-multiwell plates at a density of $2 \times 10^{5}$ cells per well and allowed to replicate overnight at $37{ }^{\circ} \mathrm{C}(5 \%$ of $\mathrm{CO}_{2}$ and humidified atmosphere). After 18 hours the DMEM was replaced by fresh medium for the positive control $(100 \%$ viability) and by medium with the AuNPs@POM at different concentrations $\left(0.1,0.07,0.05\right.$ and $\left.0.02 \mathrm{mg} \mathrm{mL}^{-1}\right)$. The cells were then incubated for 24 hours. After removal of the solutions and washing the cells twice with PBS each cell experiment was harvested with trypsin. Afterwards each of the cell experiments were resuspended in medium and transferred to an Eppendorf vial, centrifuged ( $6 \mathrm{~min} / 1260 \mathrm{rpm})$. In the case of the cells incubated with AuNPs@POM a dark precipitate could clearly be observed at the bottom of the Eppendorf vials corresponding to the cells with internalised AuNPs@POM. The supernatant from the centrifugation was discarded and the cells were resuspended in $1 \mathrm{~mL}$ of PBS. Finally, all of the cell samples were centrifuged and resuspended in buffer to be stained with a commercial kit (Annexin V-FITC Apoptosis Detection Kit, ref. ANXVFK-100T) from Immunostep, S.L. and then incubated in the dark at room temperature for 15 minutes. Flow cytometry data were collected on a FACSAria ${ }^{\text {TM }}$ (Becton Dickinson Company) flow cytometer.

\section{Cell cycle analysis by flow cytometry}

Cells for cell cycle analysis were prepared in the same manner as for apoptosis/necrosis analysis using flow cytometry. However, following incubating cells with AuNPs@POM for $24 \mathrm{~h}$, harvesting the cells and centrifuging for $6 \mathrm{~min}$, the supernatant was discarded and the cells were resuspended in $1 \mathrm{~mL}$ of PBS. This suspension was centrifuged one more time for $6 \mathrm{~min}$ at $1260 \mathrm{rpm}$ and resuspended in $200 \mu \mathrm{L}$ of PBS. Subsequently $1 \mathrm{~mL}$ of cold $70 \%$ ethanol was added dropwise under vortex shaking. Cells were stored at $4{ }^{\circ} \mathrm{C}$ and overnight and the following day were centrifuged one final time before being resuspended in a buffer containing $50 \mu \mathrm{g} \mathrm{mL} \mathrm{m}^{-1}$ of propidium iodide (PI) and $100 \mu \mathrm{g} \mathrm{mL}^{-1}$ of RNAse A and incubated at room temperature for 30 minutes in the dark. The cell cycle was analysed by flow cytometry using a FACSArray ${ }^{\mathrm{TM}}$ (Becton Dickinson Company).

\section{ICP analysis}

$2 \times 10^{5}$ of B16 and Vero cells were seeded in 12-multiwell plates and allowed to replicate overnight at $37{ }^{\circ} \mathrm{C}\left(5 \% \mathrm{CO}_{2}\right.$ and humidified atmosphere). After $24 \mathrm{~h}$ the medium was removed and another one containing AuNPs@POM at $0.1 \mathrm{mg} \mathrm{mL}{ }^{-1}$ was added $\left(V_{\mathrm{f}} \mathrm{H}_{2} \mathrm{O}<10 \%\right)$. The cells were left for another $24 \mathrm{~h}$ to allow their internalisation. In the case of the control cell samples, i.e. cells without AuNPs@POM for cell counting and for blank subtraction, the medium was replaced with fresh one. Thereafter, cells with and without AuNPs@POM were thoroughly washed with PBS, and harvested with trypsin. Afterwards medium 
for trypsin neutralisation was added and the cells were transferred from each plate to an individual Eppendorf vial. Following the centrifugation (6 $\mathrm{min} / 1260 \mathrm{rpm})$ the supernatants were discarded and cells processed for ICP analysis (see below for further details). Blank cells (without AuNPs@POM) that had been seeded for cell counting were resuspended in fresh medium directly after discarding their supernatants and were counted with the use of Trypan blue. To digest the samples for ICP analysis, cells pellets and the $100 \%$ sample of the AuNPs@POM from centrifugation were each treated with $100 \mu \mathrm{L}$ of Piranha solution $(3: 185 \%$ sulfuric acid : $50 \%$ hydrogen peroxide) for $1 \mathrm{~h}$ followed by $300 \mu \mathrm{L}$ aqua regia (1:3 nitric: hydrochloric acid) for $3 \mathrm{~h}$. Subsequently the samples were incubated at $60{ }^{\circ} \mathrm{C}$ for $15 \mathrm{~min}$ and diluted with Milli-Q water to $20 \mathrm{~mL}$. Samples were evaluated by ICP-AES and or ICP-MS (Optima 8300, Perkin Elmer).

\section{Acknowledgements}

Financial support by the Fundación General CSIC (Programa ComFuturo) and the ERC-Starting Grant 239931-NANOPUZZLE is acknowledged. The authors would like to acknowledge the use of Servicio General de Apoyo a la Investigación (SAI) and The Advanced Microscopy Laboratory (LMA-INA) for offering access to their instruments and expertise. The authors also acknowledge J. Godino of the Instituto Aragonés de Ciencias de la Salud (IACS) for access to the flow cytometry equipment and J. C. Raposo of the Servicio Central de Análisis de Bizkaia from SGIker of Universidad del País Vasco (EHU) for the ICP technical support. We also thank F. Luvi and A. Bird for fruitful discussions.

\section{Notes and references}

1 R. A. Sperling and W. J. Parak, Philos. Trans. R. Soc., A, 2010, 368, 1333.

2 M. Pérez-Hernández, P. del Pino, S. G. Mitchell, M. Moros, G. Stepien, B. Pelaz, W. Parak, E. Gálvez, J. Pardo and J. M. de la Fuente, ACS Nano, 2015, 9, 52.

3 A. V. Liopo and A. A. Oraevsky, Nanoparticles as Contrast Agents for Optoacoustic Imaging, in Nanotechnology for Biomedical Imaging and Diagnostics: From Nanoparticle Design to Clinical Applications, ed. M. Y. Berezin, John Wiley \& Sons, Inc., Hoboken, NJ, 2014.

4 P. D. Howes, R. Chandrawati and M. M. Stevens, Science, 2014, 346, 53.

5 R. M. Fratila, S. G. Mitchell, P. del Pino, V. Grazú and J. M. de la Fuente, Langmuir, 2014, 30, 15057.

6 A. Albanese, P. S. Tang and W. C. W. Chan, Annu. Rev. Biomed. Eng., 2012, 14, 1; L. Shang, K. Nienhaus and G. Ulrich Nienhaus, J. Nanobiotechnol., 2014, 12, 5.

7 Y. Wang, J. He, C. Liu, W. H. Chong and H. Chen, Angew. Chem., Int. Ed., 2015, 54, 2022; A. R. Tao, S. Habas and P. Yang, Small, 2008, 4, 310.

8 Y. Liu and B. Yan, Comb. Chem. High Throughput Screening, 2011, 14, 191.
9 M. T. Pope, Polyoxoanions: synthesis and structure, in Comprehensive Coordination Chemistry II: Transition Metal Groups, ed. A. G. Wedd, Elsevier Science, New York, NY, USA, 2004, vol. 4, p. 635.

10 X. López, J. J. Carbó, C. Bo and J. M. Poblet, Chem. Soc. Rev., 2012, 41, 7537.

11 B. Keita, T. B. Liu and L. Nadjo, J. Mater. Chem., 2009, 19, 19; S. G. Mitchell and J. M. de la Fuente, J. Mater. Chem., 2012, 22, 18091.

12 Y. F. Wang and I. A. Weinstock, Chem. Soc. Rev., 2012, 41, 7479.

13 I. V. Kozhevnikov, Chem. Rev., 1998, 98, 171.

14 T. Yamase, J. Mater. Chem., 2005, 15, 4773.

15 J. T. Rhule, C. L. Hill, D. A. Judd and R. F. Schinazi, Chem. Rev., 1998, 98, 327.

16 G. Geisberger, S. Paulus, E. Besic Gyenge, C. Maake and G. R. Patzke, Small, 2011, 7, 2808.

17 H. Stephan, M. Kubeil, F. Emmerling and C. E. Müller, Eur. J. Inorg. Chem., 2013, 1585.

18 K. Stroobants, V. Goovaerts, G. Absillis, E. Moelants, P. Proost and T. N. Parac-Vogt, Chem. - Eur. J., 2014, 20, 9567.

19 N. Gao, H. Sun, K. Dong, J. Ren, T. Duan, C. Xu and X. Qu, Nat. Commun., 2014, 5, 3422; S. Vanhaecht, G. Absillis and T. N. Parac-Vogt, Dalton Trans., 2013, 42, 15437.

20 M. Colombo, S. Carregal-Romero, M. F. Casula, L. Gutiérrez, M. P. Morales, I. B. Böhm, J. T. Heverhagen, D. Prosperi and W. J. Parak, Chem. Soc. Rev., 2012, 41, 4306; T. L. Doane and C. Burda, Chem. Soc. Rev., 2012, 41, 2885; K. Saha, S. S. Agasti, C. Kim, X. N. Li and V. M. Rotello, Chem. Rev., 2012, 112, 2739.

21 Z. Lang, I. Maicas Gabas, X. López, A. Clotet, J. M. de la Fuente, S. G. Mitchell and J. M. Poblet, New J. Chem., 2016, DOI: 10.1039/C5NJ02773J.

22 M. J. Manos, J. D. Woollins, A. M. Z. Slawin and T. A. Kabanos, Angew. Chem., Int. Ed., 2002, 15, 2801.

23 G. J. Zhang, B. Keita, R. N. Biboum, F. Miserque, P. Berthet, A. Dolbecq, P. Mialane, L. Catala and L. Nadjo, J. Mater. Chem., 2009, 19, 8639.

24 A. França, B. Pelaz, M. Moros, C. Sánchez-Espinel, A. Hernández, C. Fernández-López, V. Grazú, J. M. de la Fuente, I. PastorizaSantos and L. M. Liz-Marzán, Small, 2010, 6, 89.

25 M. A. Dobrovolskaia, A. K. Patri, J. Zheng, J. D. Clogston, N. Ayub, P. Aggarwal, B. W. Neun, J. B. Hall and S. E. McNeil, Nanomedicine, 2009, 5, 106.

26 S. J. Soenen, P. Rivera-Gil, J.-M. Montenegro, W. J. Parak, S. C. De Smedt and K. Braeckmans, Nano Today, 2011, 6, 446.

27 Q. Chen, L. Yang, C. Zheng, W. Zheng, J. Zhang, Y. Zhou and J. Liu, Nanoscale, 2014, 6, 6886.

28 H. K. Daima, P. R. Selvakannan, A. E. Kandjani, R. Shukla, S. K. Bhargava and V. Bansal, Nanoscale, 2014, 6, 758.

29 W. Zheng, L. Yang, Y. Liu, X. Qin, Y. Zhou, Y. Zhou and J. Liu, Sci. Technol. Adv. Mater., 2014, 15, 035010.

30 Q. Wu, S.-K. Qin, F.-M. Teng, C.-J. Chen and R. Wang, J. Hematol. Oncol., 2010, 3, 43.

31 M. Mahmoudi, K. Azadmanesh, M. A. Shokrgozar, W. S. Journeay and S. Laurent, Chem. Rev., 2011, 111, 3407. 
32 I. E. León, V. Porro, S. Astrada, M. G. Egusquiza, C. I. Cabello, M. Bollati-Fogolin and S. B. Etcheverry, Chem.Biol. Interact., 2014, 222, 87.

33 S. Sabella, V. Brunetti, G. Vecchio, A. Galeone, G. Maiorano, R. Cingolani and P. Pompa, J. Nanopart. Res., 2011, 13, 6821.
34 H.-K. Yang, M.-M. Su, L.-J. Ren, J. Tang, Y.-K. Yan, W.-K. Miao, P. Zheng and W. Wang, Eur. J. Inorg. Chem., 2013, 1381.

35 C. Yvon, A. J. Surman, M. Hutin, J. Alex, B. O. Smith, D.-L. Long and L. Cronin, Angew. Chem., Int. Ed., 2014, 126, 3404. 